\title{
Fates of Rare Species under Siege from Invasion: Persistence of Coccinella novemnotata Herbst in Western North America alongside an Invasive Congener
}

\author{
Edward W. Evans* \\ Department of Biology, Utah State University, Logan, UT, United States
}

Species invading new geographic regions may threaten continued existence of similar, indigenous relatives, particularly those species whose rarity may reflect an already tenuous existence. The spectacular colonization of North America in recent decades by Coccinella septempunctata L. has generated widespread concern over potentially adverse effects on population viability of native species of ladybird beetles (Coccinellidae).

OPEN ACCESS

Edited by:

António Onofre Soares, University of the Azores, Portugal

Reviewed by:

David Richard Nash,

University of Copenhagen, Denmark

Pim Edelaar,

Universidad Pablo de Olavide, Spain

Peter Michael James Brown,

Anglia Ruskin University,

United Kingdom

*Correspondence:

Edward W. Evans

ted.evans@usu.edu

Specialty section:

This article was submitted to

Behavioral and Evolutionary Ecology,

a section of the journal

Frontiers in Ecology and Evolution

Received: 29 August 2017 Accepted: 17 November 2017

Published: 05 December 2017

Citation:

Evans EW (2017) Fates of Rare Species under Siege from Invasion:

Persistence of Coccinella novemnotata Herbst in Western North

America alongside an Invasive

Congener. Front. Ecol. Evol. 5:152.

doi: 10.3389/fevo.2017.00152
Coccinella novemnotata Herbst in particular has been hypothesized to be at great risk, as this species apparently dwindled in numbers across much of North America during the twentieth century. Here results of sampling diverse habitats over three decades are examined to address the fate of $C$. novemnotata in the intermountain region of western North America following the establishment of C. septempunctata during the 1990s. Alfalfa fields have served as a major habitat for $C$. novemnotata in the intermountain west. Sweep sampling in the late 1980 s and early 1990 s demonstated that $C$. novemnotata and $C$. septempunctata were both rare members of the alfalfa lady beetle community. Subsequent sampling in alfalfa over the next two decades revealed that populations of C. septempunctata increased greatly, while populations of $C$. novemnotata remained low but persistent. Similarly, modest numbers of $C$. novemnotata were found continuing to persist, often alongside large numbers of $C$. septempunctata, in a variety of other habitats, including sagebrush steppe and weed-infested rangeland and riparian sites. Morphological comparison of these individuals of $C$. novemnotata with museum specimens collected throughout the twentieth century revealed no significant difference in mean body size between these recently and previously collected individuals, nor any significant long-term decrease in body size following the arrival of $C$. septempunctata, as might reflect increasing food limitation for larval $C$. novemnotata. Collectively these results indicate that even in the face of invasion by a dominant competitor, $C$. novemnotata has maintained an ecological foothold in the intermountain west of North America, occurring in diverse habitats including both those supporting low and high numbers of the invader. The availability of these diverse habitats across a heterogeneous landscape may promote persistence less tenuous, even as confronted with invasion, than the low abundance of C. novemnotata alone might suggest.

Keywords: competition, habitat preference, invasive species, population viability, species displacement 


\section{INTRODUCTION}

Invasive species often fundamentally transform invaded communities and ecosystems (Vitousek et al., 1996; Ricciardi et al., 2013). One major, continuing concern is that invasive species are a key cause of loss of biodiversity in threatening native species with extinction (Elton, 1958; Wilson, 1992; Wilcove et al., 1998). Reduced population sizes and, in the extreme, extinctions within many groups of native species appear most often caused by invasive species through interactions across trophic levels, such as predation, herbivory and disease, with interspecific competition playing a lesser and less clear role (Davis, 2003; Sax et al., 2007; Kraus, 2015; Sugiura, 2016). Insects and arachnids may be noteworthy exceptions in this regard, however, as Gao and Reitz (2017) review many examples of competitive displacement (p. 166: "elimination of one species by another with the same ecological niche"). But in many cases, the role of invasive species in driving native species to low numbers is unclear, as competition and other species interactions are often confounded with other major factors impinging simultaneously on native species, such as habitat modification and loss (e.g., Wilcove et al., 1998; Gurevitch and Padilla, 2004; Didham et al., 2007; Berman et al., 2013; Grabock et al., 2014; Honek et al., 2016).

Ladybird beetles (Coleoptera: Coccinellidae) have often been introduced to new geographic regions for biological control, and some have become invasive (Harmon et al., 2007; Evans et al., 2011). Evaluation of impact on native relatives from worldwide species introductions of these predators illustrates the general issues surrounding the interactions of invasive and native species. The most prominent species currently among introduced lady beetles is Harmonia axyridis (Pallas). There is concern that this invasive species may be strongly, adversely affecting native lady beetles in many parts of the world (Roy and Brown, 2015; Grez et al., 2016; Roy et al., 2016; Kenis et al., 2017). In some cases, declines of native species have preceded introduction of this species (Honek et al., 2016). Adverse effects of $H$. axyridis may be caused as much by intraguild predation on eggs, larvae and pupae of native lady beetles, as by interspecific exploitative competition for shared resources (e.g., prey); the relative importance of these mechanisms is presently unclear (Bahlai et al., 2015; Roy et al., 2016).

Another introduced species of much concern is Coccinella septempunctata L. This Eurasian species became established in North America in the 1970s and 1980s (Angalet et al., 1979; Obrycki et al., 2000) and soon thereafter came to be regarded as invasive and a likely threat to native North American lady beetles (Schaefer et al., 1987; Ehler, 1990; Elliott et al., 1996). Wheeler and Hoebeke (1995) carefully and thoroughly reviewed the case of Coccinella novemnotata Herbst, detailing that this species (once common throughout North America; Gordon, 1985) declined precipitously in its abundance in northeastern North America in the 1980s and early 1990s at the same time that the ecologically very similar, introduced C. septempunctata was rapidly increasing to very high numbers. Hesler and Kieckhefer (2008) subsequently noted similarly a decline in the abundance of $C$. novemnotata in South Dakota during the two decades preceding their publication, also coinciding with the establishment of C. septempunctata (followed subsequently by $H$. axyridis). Extensive sampling by yellow sticky traps in various agricultural and natural habitats in South Dakota from 2001 to 2006 yielded no captures of C. novemnotata (Hesler and Kieckhefer, 2008). Subsequent sampling revealed continuing presence of $C$. novemnotata in this general geographic region, but in much lower numbers than C. septempunctata (Hesler et al., 2009; Koch, 2011; Bartlett et al., 2015).

The coinciding of declining abundance of $C$. novemnotata with increasing abundance of $C$. septempunctata in eastern and midwestern North America suggested that rise of the latter might be responsible for demise of the former, but both Wheeler and Hoebeke (1995) and Harmon et al. (2007) cautioned that decline in $C$. novemnotata abundance may have resulted from other causes such as changing land use or disease. The importance of alternative causes received support from subsequent documentation that $C$. novemnotata's steep decline in Missouri occurred well before C. septempunctata arrived (Fothergill and Tindall, 2010; Diepenbrock et al., 2016). Nonetheless, the arrival of C. septempunctata and its potential competitive and predatory impact on C. novemnotata, as explored in the laboratory (Hoki et al., 2014; Kajita et al., 2014; Turnipseed et al., 2014, 2015; Ugine and Losey, 2014; Tumminello et al., 2015), raises the possibility that C. septempunctata may now diminish prospects for recovery, and indeed may drive to critically lower levels, populations of C. novemnotata previously reduced to low numbers even before its arrival.

Here I examine the population status of $C$. novemnotata following the establishment of C. septempunctata in the North American intermountain west (i.e., the geographic region lying between the Rocky and Sierra Nevada mountains). As elsewhere across the continent, $C$. novemnotata was a prominent species in this region, and in Utah in particular, through much of the twentieth century (e.g., Goodharzy and Davis, 1958). I assess the current status of $C$. novemnotata by examining its abundance in a variety of habitats over the past 30 years, and include comparison of its relative abundance vs. that of C. septempunctata and other congeneric, native species (especially C. transversoguttuta richardsoni Brown, the most common, widespread such species in the region). I also assess its status by comparing body size of individual adults (potentially reflecting larval experience; Evans, 2000; Losey et al., 2012) that were collected in recent years vs. the first seven decades of the twentieth century (as based on museum specimens). The results are evaluated in light of the risk of extinction that interspecific competition may pose in general as associated with species invasions.

\section{MATERIALS AND METHODS}

\section{Field Sampling}

The abundances of $C$. novemnotata, C. septempunctata, C. transversoguttuta, and the two additional Coccinella species (C. monticola Mulsant and C. trifasciata perplexa Mulsant) that were also encountered in some habitats, were quantified 
TABLE 1 | Summary of sweep sampling conducted in alfalfa fields in 1988-1989 and during 1992-2013 ${ }^{\mathrm{b}}$, from which the numbers of individuals of adult lady beetles (Coccinella spp.) collected were determined.

\begin{tabular}{|c|c|c|c|c|c|}
\hline Year(s) & Location(s) & Sampling months & No. of fields & No. of dates & \# of sweeps (total) \\
\hline 1988 & SW \& central UT & May-June & 11 & 1 & $200(2,200)$ \\
\hline 1988 & SW \& central UT & July & 13 & 1 & $250-750(6,950)$ \\
\hline 1988 & Northern UT & June-August & 3 & $5-6$ & $200-400(4,800)$ \\
\hline 1989 & Northern UT & May-September & $6-11^{a}$ & 5 & $250(9,000)$ \\
\hline $1992-2013^{b}$ & Northern UT & May & $1-17^{\mathrm{C}}$ & 1 & $45-600(27,225)$ \\
\hline
\end{tabular}

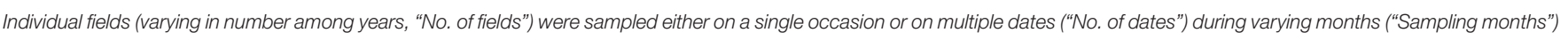

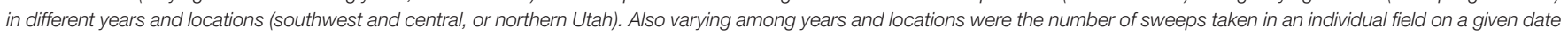
("No. of sweeps"), and the total number of sweeps taken in all fields on all dates ("total").

${ }^{a}$ The number of fields sampled on a given date during May-September 1989.

byears in which fields were sampled included 1992-1994, 1997-2006, and 2013.

c The number of fields sampled in a given year during 1992-2013.

TABLE 2 | Summary of sampling by visual searching in various habitats in 1988-2015, from which the numbers of individuals of adult lady beetles (Coccinella spp.) encountered were determined.

\begin{tabular}{|c|c|c|c|c|}
\hline Habitat & Year(s) & Sampling months & No. min/session & total No. of $\min (h)$ \\
\hline Alfalfa $^{a}$ & 1988 & September & untimed & - \\
\hline Alfalfa $^{a}$ & 2011-2012 & May-August & untimed & - \\
\hline \multicolumn{5}{|c|}{ Sagebrush steppe } \\
\hline Montane & $2000-2009^{b}$ & May-June & 20-620 & $1,500(25 \mathrm{~h})$ \\
\hline Foothills & $1994-2001^{b}$ & May-June & Untimed & - \\
\hline Rangeland & $2012-2015^{b}$ & March-July & $15-220$ & 4,800 (80 h) \\
\hline Riparian & $1995-2011^{\mathrm{b}}$ & May-August & Untimed & - \\
\hline
\end{tabular}

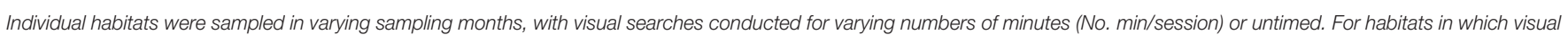
searching was timed, the total length of time ["total No. of min (h)]" is given for all searching sessions combined.

a Alfalfa was unsprayed in 1988, and sprayed with sugar solution in 2011-2012.

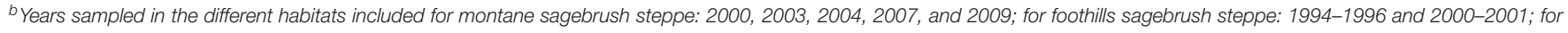
rangeland: each year during 2012-2015; and for riparian habitat: 1995-1996, 1999-2004, and 2011.

by sampling during 1988-2015 in a variety of habitats in Utah (especially northern Utah). Depending on a given sampling technique (as described below), abundance within a habitat was assessed as the number of individuals collected per unit of sampling effort, and/or as the number (relative abundance) in comparison to the number of individuals of all Coccinella spp. combined in the sample. As explained below, much of the sampling occurred in alfalfa fields but additional sampling occurred in a variety of natural and semi-natural habitats; in both settings this sampling, as analyzed and summarized here, was often conducted as adjunct to another, primary purpose for working in the habitat.

\section{Growers' Alfalfa Fields}

Multiple species of lady beetles, including C. novemnotata, C. septempunctata, and C. transversoguttata, forage as adults (feeding especially on aphids) and reproduce when prey numbers are high in alfalfa fields in the intermountain west (Goodharzy and Davis, 1958; Evans and Youssef, 1992). Sweep sampling was conducted in 1988-2013 in alfalfa fields to which growers had not applied insecticides to the current crop (Table 1). A standard, 38 $\mathrm{cm}$ diameter, cloth sweep net was used on all occasions. The net was used to sweep a $180^{\circ}$ arc through the canopy of the alfalfa
(40-70 cm high) at $1 \mathrm{~m}$ intervals along transects with the number of sweeps per field, and in all fields combined, varying among years (Table 1). The contents of the net were examined (either in the field or in the lab following transfer to plastic storage bags that were placed in the freezer) at intervals of 15-50 sweeps (as varying among years). Sweep sampling was conducted between 1,000 and $1,600 \mathrm{~h}$ on calm, clear days. All adults of Coccinella collected by sweeping were identified to species and counted.

Varying numbers of fields were sampled by sweep net on varying dates in different years of the study (as summarized in Table 1). In 1988, eleven fields were each sampled once from 28 May through 2 June, and again (along with two additional fields) from 6 to 8 July in southwestern and central Utah (Washington, Iron, Beaver, Millard, Sevier and Juab counties; 800-1,700 m elevation). Also in 1988, three fields in northern Utah (Cache Valley; 1,300-1,400 m) were each sampled on five or six dates between 27 June and 29 August. An additional alfalfa field in Cache Valley was found to have many lady beetles present in early September, and hence was sampled opportunistically on 6-7 September by collecting all adult lady beetles by hand as encountered in visual searching (Table 2). In 1989, a new set (i.e., not sampled in 1988) of 11 unsprayed fields in Cache Valley was sampled during each of five periods from early May through 
early September (Evans and Youssef, 1992; because of varying irrigation and cutting schedules, the number of fields that could be sampled in a given period varied from 6 to 11). Alfalfa fields in Cache Valley also were sampled by sweep net during mid to late May in each of 14 years during 1992-2013 (Table 1), with the number of fields sampled in a given year varying from 1 to 17 (in most cases, fields sampled in a given year were not sampled in the following year).

\section{Application of Sugar Solution to Alfalfa}

In 1991-1997, eight experiments of similar design were conducted at alfalfa fields in Cache Valley wherein a sugar solution (intended to serve as an artificial honeydew) was applied to the foliage during the first crop (late April-early June). Two experiments were conducted in each year in 1991-1993, with single experiments in 1996 and 1997. In any given experiment in any given year, 6 to 10 plots of $120-400 \mathrm{~m}^{2}$ each were created in an alfalfa field, with adjacent plots $10-40 \mathrm{~m}$ apart, and half of these plots were selected randomly to be sprayed with $150 \mathrm{~g}$ sucrose per 1 of water (details of experimental design are given in Evans and Swallow, 1993; Evans and Richards, 1997; Evans, 2015). Five to fifteen sweeps (depending on the particular experiment) were taken in individual plots (including control plots sprayed with water alone) from 1 to 5 days after sugar was applied. The numbers of adults of C. novemnotata, C. septempunctata, and C. transversoguttuta (the three Coccinella spp, collected) were counted from these sweeps (540-720 sweeps from all control and sugar plots combined for an individual experiment).

Visual searches and hand collections of Coccinella adults were conducted in alfalfa sprayed with sugar, as well as in other habitats as noted below (Table 2). In 2011-2012, from May through August, strips of alfalfa $(25 \times 2 \mathrm{~m})$ in fields in Cache Valley were sprayed with sugar solution $(150 \mathrm{~g}$ sucrose per 1 of water) at intervals of 2 to 4 weeks in each of three fields in each year (to obtain adult coccinellids for laboratory experiments). From 1 to 4 days after spraying, the plots were visited and all adults of Coccinella were hand-collected as encountered in visual searching (because adults differed little among species in where on the host plant they occurred, and in how conspicuous they were, these hand collections could be conducted with minimal bias). Cutting of the first crop was delayed until late June in 2011, enabling the alfalfa fields to be sprayed and sampled for much of the month. The first crop was cut at the end of May in 2012 and spraying was not again initiated until July (when the alfalfa had grown back sufficiently). Consequently, no lady beetle sampling was conducted in June 2012.

\section{Sagebrush Steppe}

During 5 years in 2000-2009, timed visual searches for lady beetles were conducted during May and early June at montane sites in northern Utah (Cache County; 1,900-2,400 m elevation) dominated by sagebrush (Artemisia spp.). Woody vegetation at these treeless sites also included bitterbrush (Purshia tridentata [Pursh] DC) and rabbitbrush (Ericameria spp.). All adults of Coccinella were collected as encountered while systematically searching the vegetation for a measured amount of time
(Table 2). Less formal (untimed) visual searching for adult ladybirds in sagebrush steppe was conducted at foothills sites at lower elevation $(1,500 \mathrm{~m})$ in Cache County on a number of occasions in March-June during 5 years in 1994-2001 (Table 2; all adults encountered during these searches were collected, or recorded by species).

\section{Rangelands Dominated by Grasses and Forbs}

Visual searches for adult lady beetles were made while pursuing field studies of biological control of noxious weeds on public lands in Utah. The most consistent, extensive assessment was completed in 2012-2015 (March-July) in conjunction with censuses, conducted every 1 to 7 days, of infestations of Dalmatian toadflax (Linaria dalmatica (L.) Miller, Plantaginaceae) at two sites (referred to below as Lakepoint and Pine Canyon) on formerly grazed, open lands in Tooele County, and occasionally also in similar habitat at Antelope Island State Park in Davis County (site elevations: 1,300$1,400 \mathrm{~m}$ ). Vegetation in addition to the toadflax at these sites included a mixture of introduced and native grasses, forbs, and scattered shrubs (sagebrush, rabbitbrush, and snakeweed [Gutierrezia] spp.). Adults of Coccinella were recorded as encountered incidentally while censusing individual toadflax stems for biocontrol assessment, as was the presence/absence of aphids feeding on each stem. Adults of Coccinella were recorded also as encountered during timed searches of all vegetation present at the study sites on many occasions following censusing of toadflax stems. Time spent searching specifically for adult lady beetles during individual visits to these sites (Table 2) varied over the 4 years depending on circumstances, including the tasks at hand for assessing biocontrol of the weed (the primary purpose of the visit) and the number of individuals visiting the site.

Opportunistic observations of C. novemnotata were also made in 2012-2014 during visits to other rangeland sites (1,700$1,800 \mathrm{~m}$ ). These included sites in Davis and Tooele counties that were infested with Dalmatian toadflax, and sites in Juab and Tooele counties that were infested with squarrose knapweed (Centaurea virgata Lam. ssp. squarrosa Gugler).

\section{Riparian Zones}

Untimed visual searches were conducted for Coccinella adults at riparian sites $(1,900-2,000 \mathrm{~m})$ in northern Utah in conjunction with field studies of infestations of Canada thistle (Cirsium arvense [L.] Scop., Asteraceae). Searches for lady beetles were undertaken on one to three dates (May-August) at sites in Rich County during each of nine summers from 1995 to 2011 (Table 2). Vegetation searched at riparian sites included especially the thistle, sagebrush, and currant (Ribes spp.), each of which at times supported populations of aphids. The riparian zones (extending up to $60 \mathrm{~m}$ on either side of a creek) were surrounded by sagebrush steppe.

\section{Measurements of Adult Body Size for C. novemnotata}

Pinned specimens of C. novemnotata deposited in the Utah State University Insect Collection, collected in northern Utah and southeast Idaho in 1904-1974 (62 females and 52 males), and 
individuals collected during the present study in northern Utah in 2011-2012 (30 females and 22 males), were measured for body size by viewing the dorsum through a microscope. Length from the anterior tip of the head to the posterior tip of the elytra, and width at its maximum across the elytra, were measured to the nearest $0.01 \mathrm{~mm}$.

\section{Statistical Analyses}

Much of the data collected in this study was simply summarized to describe broad trends. In addition, several statistical tests were applied to individual data sets as follows.

The numbers of adults of $C$. novemnotata and C. septempunctata per 100 sweeps in alfalfa in mid to late May vs. the year of sampling (1992-2013), and the numbers of adults of $C$. novemnotata vs. C. septempunctata in a given year, were examined using Spearman rank correlation (SAS Institute, 2011).

Using one-way analysis of variance (SAS Institute, 2011), the individual abundances of the three species (i.e., number of adults per 100 sweeps, as determined from all plots combined) in the four sugar spray experiments conducted in the springs of 19911992, were compared with their abundances in the four sugar spray experiments conducted in the springs of 1993-1997. In the analysis, the number of adults per 100 sweeps as obtained from each experiment was used to compare means between 1991-1992 and 1993-1997 (i.e., $n=4$ estimates of abundance for each of the two time periods). To meet assumptions of normality, the mean number of adults of each species per 100 sweeps for all plots combined in a given experiment was transformed by taking the square root prior to analysis.

Variation in body size of individuals of each sex (measured as length $\times$ width; Losey et al., 2012) vs. year of collection was examined by linear regression (SAS Institute, 2011) for individuals collected in 1904-1974. Mean body sizes of adults were compared for individuals collected in 1904-1974 vs. 20112012 for each sex using analysis of variance (SAS Institute, 2011).

\section{RESULTS}

\section{Growers' Alfalfa Fields}

In the late 1980s, individuals of C. novemnotata were only rarely encountered in Utah alfalfa fields. No individuals of C. novemnotata (or of C. septempunctata) occurred among the 487 adult lady beetles (primarily individuals of Hippodamia spp.) collected by sweeping alfalfa fields in late May-early June 1988 in central and southwest Utah, vs. twelve adults of $C$. transversoguttuta (0.55/100 sweeps). Only two individuals (0.003/100 sweeps) of $C$. novemnotata (and also of C. septempunctata) occurred among 1,733 adult lady beetles collected from fields sampled in early July 1988, along with 46 individuals of C. transversoguttuta (0.66/100 sweeps) and one additional adult of Coccinella (an individual of C. monticola).

No individuals of C. novemnotata or C. septempunctata (i.e., fewer than 0.025/100 sweeps of either species) occurred among 953 adult lady beetles collected in northern Utah (Cache Valley) alfalfa fields in summer 1988; eight adults of C. transversoguttuta

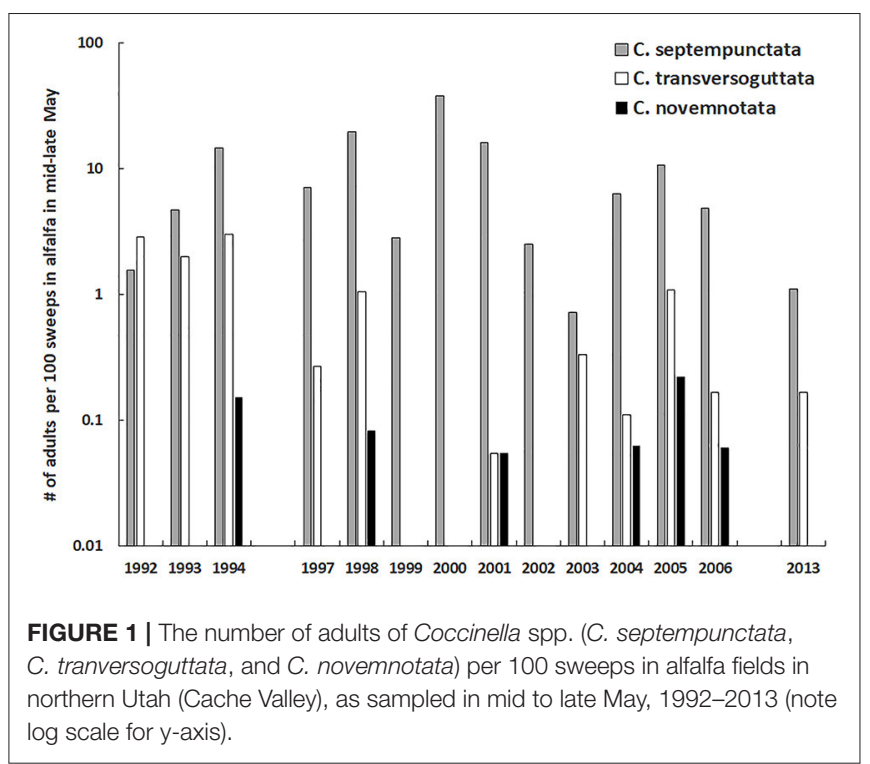

$(0.17 / 100$ sweeps) were collected from late June through late August in these samples. Two individuals of C. novemnotata (and three of C. transversoguttuta, but no C. septempunctata) occurred among 463 adult lady beetles hand collected as encountered on 6-7 September 1988 in a Cache Valley alfalfa field. In 1989 , only four individuals of $C$. novemnotata (0.04/100 sweeps) occurred among 1,333 adult lady beetles collected from alfalfa fields in Cache Valley from early May through early September. In addition, there were 14 individuals of C. transversoguttuta (0.16/100 sweeps; as with $C$. novemnotata, collected from late May through early Sept), and one individual of C. septempunctata (0.01/100 sweeps; collected in early August).

In the 1990s C. novemnotata continued to be encountered rarely in alfalfa fields. During this time C. septempunctata became common, greatly outnumbering the two native species C. novemnotata and C. transversoguttuta by the mid-1990s in alfalfa fields of northern Utah (Figure 1 and Table 3). The number of adults of C. septempunctata per 100 sweeps in mid to late May varied widely among years in 19922013, with no long-term trend (Figure 1; Spearman rank correlation for abundance vs. year, $\left.r_{\mathrm{s}}=-0.18, P=0.53\right)$. Few adults of $C$. novemnotata were swept throughout 19922013 (with an overall mean of 0.05 individuals/100 sweeps, vs. 0.34/100 sweeps for C. transversoguttuta and 9.48/100 sweeps for C. septempunctata). Adults of $C$. novemnotata were collected in only 6 of the 14 years in which sweeps were taken, but showed no tendency to become less abundant over time (Figure 1; Spearman rank correlation for abundance vs. year, $\left.r_{\mathrm{s}}=0.20, P=0.49\right)$. Among individual years over this period, numbers of adults of C. novemnotata and C. septempunctata were positively correlated $\left(r_{\mathrm{s}}=0.56, P=0.04\right)$.

\section{Application of Sugar Solution to Alfalfa}

In 1991-1997, adults of three Coccinella spp. were swept from plots in which experiments were conducted with application of 
TABLE 3 | The percentage of lady beetle adults belonging to Coccinella spp. represented by C. novemnotata (Cn), C. transversoguttuta (Ct), C. septempunctata (Cs), C. monticola $(\mathrm{Cm})$, and C. trifasciata (Ctf), as collected in different habitats.

\begin{tabular}{|c|c|c|c|c|c|c|c|c|}
\hline \multirow[t]{2}{*}{ Habitat } & \multirow[t]{2}{*}{ Years } & \multirow[t]{2}{*}{ Method } & \multirow[t]{2}{*}{$N$} & \multicolumn{5}{|c|}{ Percent } \\
\hline & & & & Cn & Ct & Cs & $\mathrm{Cm}$ & Ctf \\
\hline Alfalfa & 1992-2013 & Sweep & 2,582 & 0.5 & 3.6 & 95.9 & - & - \\
\hline Alfalfa* & 1991-1997 & Sweep & 488 & 3.1 & 28.5 & 68.4 & - & - \\
\hline Alfalfa* & 2011-2012 & Hand & 4,124 & 0.3 & 23.6 & 76.1 & - & - \\
\hline \multicolumn{9}{|c|}{ Sagebrush steppe } \\
\hline Montane & 2000-2009 & Hand & 753 & 1.2 & 79.0 & 2.9 & 16.9 & - \\
\hline Foothills & 1994-2001 & Hand & 516 & 1.4 & 15.3 & 82.9 & - & 0.4 \\
\hline Rangeland & 2012-2015 & Hand & 4,979 & 7.1 & 0.5 & 92.4 & - & - \\
\hline Riparian & 1995-2011 & Hand & 362 & 3.9 & 57.5 & 8.3 & 25.7 & 4.4 \\
\hline
\end{tabular}

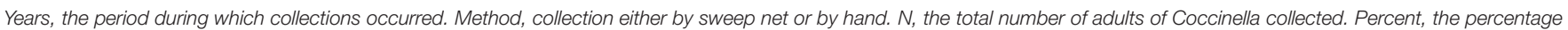

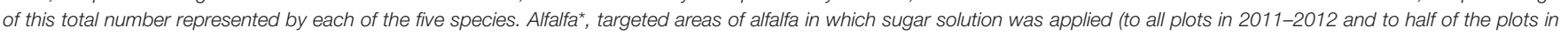
1991-1997; see section Materials and Methods).

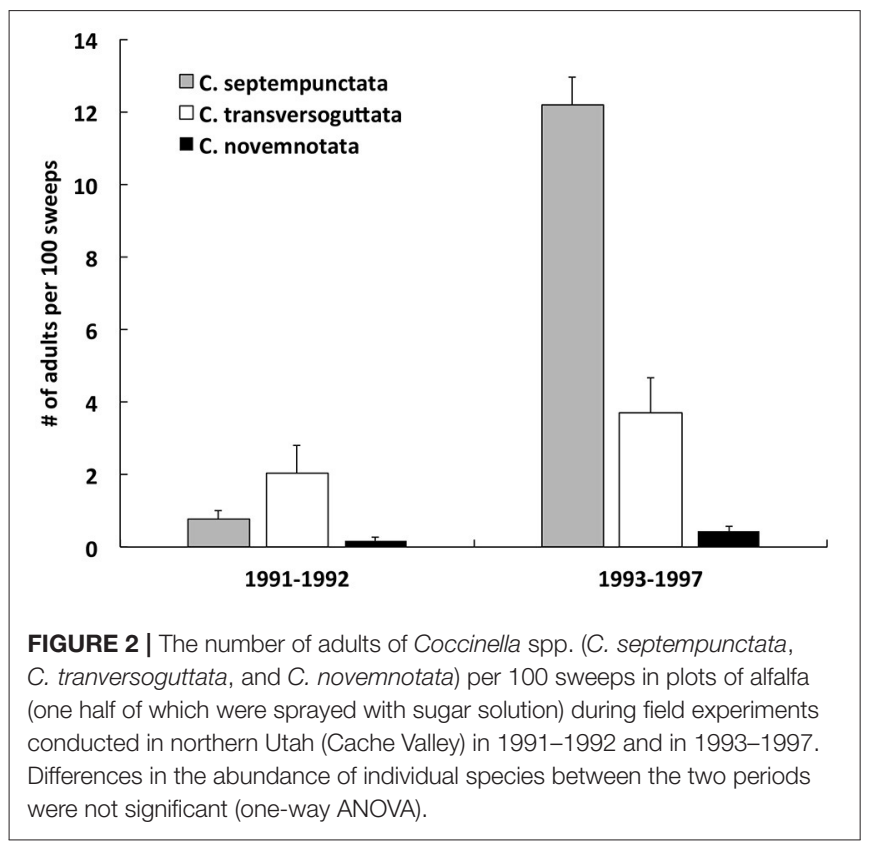

sugar solution to the first (spring) crop of alfalfa (Table 3). An order of magnitude more adults of C. septempunctata occurred in plots during 1994-1997 vs. 1991-1992 [Figure 2; one-way ANOVA: $\left.F_{(1,6)}=255.04, P<0.0001\right]$. Very low numbers of $C$. novemnotata, and low numbers of $C$. transversoguttuta, occurred in both plots treated with sugar solution and control plots during both time periods [Figure 2; one-way ANOVA for number of individuals per 100 sweeps from all plots combined, for C. novemnotata: $F_{(1,6)}=3.66, P=0.11$, and for C. transversoguttuta: $\left.F_{(1,6)}=1.73, P=0.24\right]$.

In 2011-2012, large numbers of adults of Coccinella, dominated by C. septempunctata, were collected throughout the summer in Cache Valley from plots of alfalfa sprayed with sugar (Table 3). Absolute and relative abundances in the sprayed strips varied moderately among months, but the rank order of

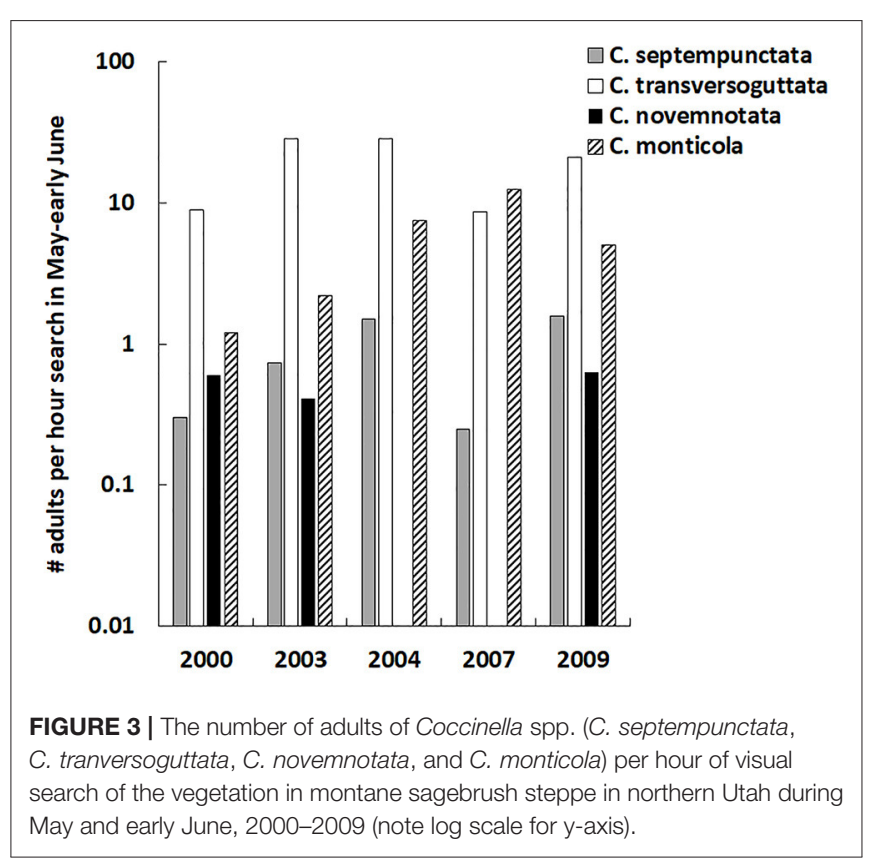

Coccinella species was consistent among all months over the 2 years, with $C$. novemnotata always accounting for $<1 \%$ of individuals in any given month.

\section{Sagebrush Steppe}

Adults of C. novemnotata occurred in very low numbers in timed hand collections in montane sagebrush steppe during 2000-2009, but were collected in 3 of 5 years (Figure 3). Adults of C. septempunctata also consistently occurred in very low numbers and were collected each year, while the most common species present was $C$. transversoguttuta, followed by C. monticola (Table 3). For all years combined, C. novemnotata and C. septempunctata were collected at rates of 0.36 and 0.88 adults per hour of search, respectively, whereas 
C. transversoguttuta and C. monticola were collected at rates of 23.8 and 5.1 adults per hour of search.

Adults of C. novemnotata were also rarely encountered in untimed hand collections in foothills sagebrush steppe in 19942001 (Table 3). Nonetheless, adults of C. novemnotata occurred in this habitat throughout these years, including in 2001 when two individuals were collected along with 36 individuals of C. septempunctata from currant bushes heavily infested with an unidentified psyllid. In contrast to its low abundance at higher elevation, C. septempunctata was the dominant species present in foothills sagebrush steppe (Table 3).

\section{Rangelands Infested with Weeds}

Lady beetles including C. novemnotata were found consistently in spring and early summer at Lakepoint and Pine Canyon in Tooele County. They varied considerably in their abundance, however, among months and years (Table 4), reflecting in part varying local availability of prey. Aphids occurred each year on Dalmatian toadflax, but varied in seasonal timing and abundance among years (e.g., they were abundant on stems in April in 2015, but did not appear on stems until June in 2013). On most sampling dates, $10 \%$ or fewer of stems were infested, but 40 $70 \%$ of stems at both sites were infested during much of May 2014 and from mid-April to mid-May 2015 when many adult lady beetles were encountered at the sites. Adult lady beetles also were abundant, however, on some occasions when aphid abundance on toadflax was low. Aphids occurring in the habitat were not restricted to toadflax, as unidentified aphid species were encountered at times on various additional host plants, including

TABLE 4 | The percentage of lady beetle adults (Coccinella spp.) at rangeland sites infested with Dalmatian toadflax represented by C. novemnotata $(\mathrm{Cn})$ and C. transversoguttuta (Ct) (vs. the third and most abundant Coccinella species present, C. septempunctata), as encountered in combined visual searches for the two sites by month for individual years.

\begin{tabular}{|c|c|c|c|c|c|}
\hline \multirow[t]{2}{*}{ Month } & \multirow[t]{2}{*}{ Species } & \multicolumn{4}{|c|}{ Year } \\
\hline & & 2012 & 2013 & 2014 & 2015 \\
\hline \multirow[t]{3}{*}{ March } & $\mathrm{Cn}$ & - & - & 14.5 & 0 \\
\hline & $\mathrm{Ct}$ & - & - & 1.8 & 0 \\
\hline & & no s & no s & $(N=55)$ & $(N=33)$ \\
\hline \multirow[t]{3}{*}{ April } & $\mathrm{Cn}$ & - & - & 4.3 & 1.5 \\
\hline & $\mathrm{Ct}$ & - & - & 0.3 & 0.4 \\
\hline & & nos & no s & $(N=300)$ & $(N=272)$ \\
\hline \multirow[t]{3}{*}{ May } & $\mathrm{Cn}$ & 9.4 & 4.1 & 3.5 & 0.7 \\
\hline & $C t$ & 1.6 & 0 & 0.4 & 0.5 \\
\hline & & $(N=319)$ & $(N=49)$ & $(N=457)$ & $(\mathrm{N}=403)$ \\
\hline \multirow[t]{3}{*}{ June } & $\mathrm{Cn}$ & 12.7 & 9.9 & 4.4 & 11.4 \\
\hline & $C t$ & 0 & 1.0 & 0 & 0 \\
\hline & & $(N=102)$ & $(N=1,053)$ & $(N=1,428)$ & $(N=105)$ \\
\hline \multirow[t]{3}{*}{ July } & $\mathrm{Cn}$ & - & 21.1 & - & - \\
\hline & $C t$ & - & 0.5 & - & - \\
\hline & & no s & $(N=403)$ & nos & no s \\
\hline
\end{tabular}

$N$, total number of Coccinella adults encountered in a given month; no s, no searches conducted during a given month. sagebrush, rabbitbrush, salsify (Tragopogon dubius Scop,), and mullein (Verbascum virgatum Stokes).

Most adult lady beetles occurring at the two sites belonged to the three species of Coccinella, with zero to ten individuals of Hippodamia in addition (especially $H$. convergens Guerin) encountered during a given visit to either site. The percentages of all individuals encountered that belonged to each of the three Coccinella species were similar between the two sites, with a substantial number of adults belonging to C. novemnotata although most individuals belonged to C. septempunctata (Table 3). Except during March 2015, individuals of $C$. novemnotata were observed in each month in each year that sites were visited, as were in most cases the much more rarely encountered individuals of C. transversoguttuta. Relative abundances of C. novemnotata and C. transversoguttuta, as they were encountered in individual months during individual years, varied from 0.7 to $21.1 \%$, and 0.3 to $1.8 \%$, respectively, of all Coccinella adults encountered (Table 4). In particular, the number of $C$. novemnotata adults encountered varied among years between 0.4 and 1.5 individuals per hour of search during May (for an overall mean of 1.1 per hour), and 1.2-6.7 individuals during June (for an overall mean of 3.9 per hour). Lady beetle larvae were abundant at times in May and June, but were not systematically identified to species during visual searches. Soft teneral adults encountered during June, however, indicated that all three species reproduced in the habitat. This was further confirmed in particular for C. novemnotata as well as C. septempunctata, with adults emerging in the laboratory after being collected as pupae at the sites in late May 2012.

Additional observations of C. novemnotata (and C. transversoguttata) were made in April-June in 20122014 during occasional visits to five other rangeland sites infested with Dalmatian toadflax. For example, 11 adults each of $C$. novemnotata and C. septempunctata plus two C. transversoguttuta adults were found in a patch of wavyleaf thistle (Cirsium undulatum [Nutt.] Spreng.) harboring abundant aphids at a site infested with toadflax on Antelope Island in mid-June 2012. At two similarly vegetated rangeland sites infested with squarrose knapweed in Tooele and Juab counties, three solitary adults of $C$. novemnotata (including one soft, teneral adult) were found (two in sweeping the knapweed, and one on sagebrush) in site visits during June 2013.

\section{Riparian Zones Infested with Weeds}

Adult ladybirds, including some $C$. novemnotata, were encountered in visits to riparian sites infested with Canada thistle. At these sites they were found on the thistle itself, on which abundant populations of an unidentified aphid were found on occasion throughout the summer months, and on sagebrush and currant shrubs. Most of the adult Coccinella collected as encountered in 1995-2011 were of C. transversoguttuta and C. monticola, and relatively few were of C. novemnotata, C. septempunctata, and C. trifasciata (Table 3). Adults of C. transversoguttuta were encountered every year (as were adults of C. monticola in each year when at least 20 adults were encountered in total). Adults of $C$. novemnotata, however, were encountered only in 1995 (in late June and early July), whereas 
adults of $C$. septempunctata were encountered in low numbers in every year (adults of C. trifasciata were encountered in 1995, 2001, and 2011).

\section{Measurements of Adult Body Size for C. novemnotata}

There was no trend over time during 1904-1974 in body size of C. novemnotata adults of either sex, as determined from pinned specimens [linear regression, body size vs. year, for females: $F_{(1,60)}=0.08, P=0.78$; for males: $\left.F_{(1,50)}=0.00, P=0.98\right]$. Individuals of each sex varied in size to a similar extent in each of the two time periods, 1904-1974 and 2011-2012, with no significant difference in body size between the two periods for either sex (1904-1974 vs. 2011-2012, $\mathrm{x}+$ SE for females: 35.63 +0.58 vs. $36.78+0.69 \mathrm{~mm}^{2}\left[F_{(1,90)}=1.43, P=0.23\right]$, and for males: $31.70+0.65$ vs. $29.95+0.60 \mathrm{~mm}^{2}\left[F_{(1,72)}=2.63\right.$, $P=0.11]$ ).

\section{DISCUSSION}

The coincidence in timing of the rapid increase in abundance of the exotic lady beetle C. septempunctata with the dramatic decrease in abundance of the formerly widespread native species C. novemnotata during the late 1900 s, coupled with the seemingly strong niche overlap between the two species, suggested competitive displacement as one possible cause for the change in population status of $C$. novemnotata in northeastern North America (Wheeler and Hoebeke, 1995; Harmon et al., 2007; Tumminello et al., 2015). In addition or alternatively, this change may have resulted also from other factors, such as changing patterns of land use, climate change, changes in prey abundance (e.g., aphids in crops), and disease (Wheeler and Hoebeke, 1995; Day and Tatman, 2006; Harmon et al., 2007). It is important therefore to consider also patterns in population status of $C$. novemnotata in other regions of North America as C. septempunctata has become well-established in these regions as well (Fothergill and Tindall, 2010; Bartlett et al., 2015; Diepenbrock et al., 2016).

In the intermountain west, C. septempunctata became wellestablished and numerous during the early 1990s following its introduction to surrounding areas in the mid to late 1980s as part of a biological control campaign against the Russian wheat aphid, Diuraphis noxia [Kurdjumov] (Evans, 1991, 2000). The results presented here from sampling alfalfa fields throughout Utah in 1988 and 1989 indicate that both C. novemnotata and C. septempunctata occurred in low numbers in these fields in these 2 years, with fewer than 0.05 adults collected per 100 sweeps. Over the next 20 years, C. novemnotata continued to occur in these low numbers in alfalfa fields, with no indication of any change in population status, even as C. septempunctata became very abundant and dominant in this habitat. For example, no significant difference occurred in the abundance of C. novemnotata as measured in sugar spray experiments in the 1990s before and after C. septempunctata became dominant. The results presented here document also that over the past three decades, individuals of $C$. novemnotata have occupied diverse habitats in Utah. As in alfalfa, they have occurred at consistently low numbers in other habitats, with only up to several individuals found per hour of search. This is the case not only in habitats where large numbers of C. septempunctata occur (foothills sagebrush steppe and rangeland sites infested with toadflax) but also in habitats supporting few individuals of C. septempunctata (montane sagebrush steppe and riparian sites).

A second means of testing for possible changes in population status of $C$. novemnotata following the introduction of C. septempunctata to the intermountain west is to consider the body sizes attained as adults by individuals of this native species, before and after the establishment of the invader. While adult body size of individual insects is generally strongly influenced by genetics (e.g., Dingle, 1984; Fox et al., 1999), it also generally reflects environmental conditions, including food availability, during growth of the individual as an immature (e.g., Gullan and Cranston, 2014). Thus the success of lady beetles as larvae in finding and consuming sufficient numbers of aphids and similar prey typically has great influence on their body size upon molting to adults (Hodek et al., 2012). A previous analysis of body size of C. transversoguttuta adults indicated no significant change in body size (in particular, no significant decrease that might reflect increasing larval competition for food) following the establishment of C. septempunctata in the intermountain west (Evans, 2000). Subsequently, Losey et al. (2012) reported unusually small body sizes of $C$. novemnotata adults collected in small numbers in Oregon, South Dakota and Nebraska in 2008-2009, and relatively small mean body size of six individuals collected early in the year in 2011 in Utah. More extensive sampling and measuring of body size for Utah populations of $C$. novemnotata in 2011-2012 as reported here, however, indicates that individuals of C. novemnotata are not significantly different in size now following widespread establishment of C. septempunctata than they were throughout the 1900 s before C. septempunctata arrived.

Thus, patterns of body size of $C$. novemnotata join patterns of abundance in suggesting relative stability over time in the intermountain west. As a relatively rare species that occurs in diverse habitats, both native and agricultural, C. novemnotata has occurred in consistently low abundance over the past three decades, much as it also has done in midwestern North America (Koch, 2011; Bartlett et al., 2015).

It is difficult to compare the present low numbers of C. novemnotata with numbers that may have been characteristic of this species in earlier years in the intermountain west. Over the past century, C. novemnotata is thought to have been much more abundant previously than in recent years in many parts of North America (Gordon, 1985; Wheeler and Hoebeke, 1995; Harmon et al., 2007; Hesler and Kieckhefer, 2008; Fothergill and Tindall, 2010; Diepenbrock et al., 2016). One published record for Utah in particular indicates that under some circumstances, adults of $C$. novemnotata occurred at much higher abundance than documented here for the recent past (i.e., from the late 1980s to the present). Goodharzy and Davis (1958) collected 2-5 adults of $C$. novemnotata per 100 sweeps throughout June-September 1956 in alfalfa fields heavily infested with a new pest to Utah, the spotted alfalfa aphid (Therioaphis maculata [Buckton]), numbers 
of which declined considerably in subsequent years with the introduction of resistant cultivars of alfalfa. These abundances of C. novemnotata are far greater than those documented here for Utah alfalfa fields in recent years, even in fields with local outbreaks of pea aphids or sprayed with sugar (such application of sugar leads to local aggregation of large numbers of adult lady beetles in general; e.g., Evans and Swallow, 1993; Evans, 2015). This comparison suggests that indeed $C$. novemnotata may have been more numerous in the past, but all that can be stated with confidence is that this species has persisted at low abundance over recent decades, consistently occurring in multiple habitats.

It is intriguing that no strongly adverse effect of C. septempunctata on C. novemnotata in the intermountain west is apparent. The highly successful initial establishment of this species in North America was a cause for widespread concern over potential adverse effects on native lady beetles in general (Schaefer et al., 1987; Ehler, 1990; Ruesink et al., 1995; Simberloff and Stiling, 1996; Obrycki et al., 2000). Indeed, it appears that in Utah the dominance of C. septempunctata in alfalfa fields has led, often through reduced availability of aphid prey, to reduced numbers of native lady beetles exploiting this habitat (Evans, 2004). However, C. novemnotata occurred in very low numbers in alfalfa even in 1988-1989, before C. septempunctata became dominant in the habitat, and the use by $C$. novemnotata of other habitats as discussed below may play a critical role in its persistence across the landscape. At times, alfalfa continues to support large numbers of aphids (especially pea aphids) and consequently also lady beetles. It is noteworthy that the appearance of C. novemnotata among these lady beetles in alfalfa coincided over the period 1992-2013 with the presence of large numbers of C. septempunctata, as both species responded to favorable conditions. However, more detailed assessment of spatial (e.g., among fields) and temporal (e.g., among years) variation in habitat suitability (e.g., aphid density) as it influenced the abundance of these lady beetles is beyond the scope of this study.

Across Utah, other habitats also continue to suit the needs of C. novemnotata, including supporting reproduction (as reflected in the occurrence of teneral adults, as noted in the section Results). Just as alfalfa in the 1950s offered emergent opportunities for C. novemnotata and other lady beetle species with new outbreaks of aphids when the spotted alfalfa aphid arrived, so too has the continuing establishment of exotic weeds (e.g., Dalmatian toadflax and Canada thistle) that at times support abundant aphids in various native and seminative habitats. In particular, in 2012-2015 C. novemnotata was second only to $C$. septempunctata among all species of lady beetles capitalizing on the occurrence of aphids on Dalmatian toadflax. Whereas $C$. novemnotata occurred less abundantly than C. transversoguttuta during this study in sagebrush steppe and riparian zones as well as in alfalfa (as also recorded by Goodharzy and Davis, 1958), C. novemnotata was much more abundant than C. transversoguttuta in rangeland sites where the toadflax grew. Individuals of $C$. novemnotata occurred in low numbers across all of these habitats, including habitats weakly as well as strongly invaded by C. septempunctata. Subtle differences in patterns of habitat use among closely related species such as
C. novemnotata, C. transversoguttuta, and C. septempunctata may hence promote their continuing presence and coexistence across landscapes diverse in both vegetation and elevation, such as the landscapes found in the intermountain west (Evans, 2004). In particular, these subtle differences may result in sufficient habitat segregation such that $C$. novemnotata can persist as a rare species in finding opportunities to reproduce that vary across both space and time among the multiple, diverse habitats that it frequents.

In summary, patterns of abundance and body size of C. novemnotata in recent years do not suggest that the population status of this native species has changed dramatically with the population explosion of C. septempunctata that followed introduction in the 1990s. As appears the case in general for indigenous organisms at risk of extinction from competition with invasive species (Davis, 2003), C. novemnotata appears to have withstood new pressures imposed by $C$. septempunctata. These pressures may join others now in preventing C. novemnotata from increasing significantly in overall abundance (Losey et al., 2012; Turnipseed et al., 2014). But although rare, C. novemnotata has maintained itself over the past three decades as a member of the aphidophagous lady beetle assemblage in multiple habitats of the intermountain west of North America. When rare native species such as $C$. novemnotata that are habitat generalists are confronted with invasion, landscape heterogeneity may be critical in promoting persistence less tenuous than their low abundance might suggest. Correspondingly, preservation and maintenance of such landscape heterogeneity may serve as a major means to promote and protect native biodiversity in the face of invasion.

\section{AUTHOR CONTRIBUTIONS}

EE: Directed and participated in the field work, completed the data analyses, and wrote the manuscript. The many individuals who assisted the author in the field work, carried out over three decades, are thanked in the Acknowledgements.

\section{ACKNOWLEDGMENTS}

I thank many students, colleagues, and enthusiastic volunteers who assisted over the years with fieldwork, including especially J. Anderson, M. Anderson, R. Aycock, K. Bailey, M. Benson, J. Bingham, V. Bolshakova, N. Carlile, N. Davidson, S. England, L. Evans, R. Evans, J. Gonzalez, D. Gunther, B. Harker, S. Higbee, J. Hunt, M. Innes, M. Johnson, Y. Kajita, A. Kalaskar, J. Kellor, K. Labrum, A. Mull, A. Nelson, N. Pitigala, D. Richards, C. Rogers, C. Simmons, J. Smith, A. Stevenson, J. Swallow, T. Toler, N. Tolley, V. Weeresekera, S. Willden, D. Wright, and N. Youssef. I also thank three reviewers for their perceptive, very helpful comments on the manuscript. This research was supported by the Utah Agricultural Experiment Station, Utah State University, and approved as journal paper number 9203. Additional funding was provided by the Utah State University Open Access Funding Initiative, USDA, National Science Foundation, and U.S. Department of Interior (Bureau of Land Management). 


\section{REFERENCES}

Angalet, G. W., Tropp, J. M., and Eggert, A. N. (1979). Coccinella septempunctata in the United States: recolonizations and notes on its ecology. Environ. Entomol. 8, 896-901. doi: 10.1093/ee/8.5.896

Bahlai, C. A., Colunga-Garcia, M., Gage, S. H., and Landis, D. A. (2015). The role of exotic ladybeetles in the decline of native ladybeetle populations: evidence from long-term monitoring. Biol. Invasions 17, 1005-1024. doi: 10.1007/s10530-014-0772-4

Bartlett, P. B., Hesler, L. S., French, B. W., Catangui, M. A., and Gritzner, J. H. (2015). Lady beetle assemblages (Coleoptera: Coccinellidae) in western South Dakota and western Nebraska and detection of reproducing populations of Coccinella novemnotata. Ann. Entomol. Soc. Am. 108, 474-486. doi: 10.1093/aesa/sav043

Berman, M., Andersen, A. N., and Ibanez, T. (2013). Invasive ants as back-seat drivers of native ant diversity decline in New Caledonia. Biol. Invasions 15, 2311-2331. doi: 10.1007/s10530-013-0455-6

Davis, M. A. (2003). Biotic globalization: does competition from introduced species threaten biodiversity? Bioscience 53, 481-489. doi: 10.1641/0006-3568 (2003)053[0481:BGDCFI]2.0.CO;2

Day, W. H., and Tatman, K. M. (2006). Changes in abundance of native and adventive Coccinellidae (Coleoptera) in alfalfa fields, in northern New Jersey (1993-2004) and Delaware (1999-2004), USA. Entomol. News 117, 491-502. doi: 10.3157/0013-872X(2006)117[491:CIAONA]2.0.CO;2

Didham, R. K., Tylianakis, J. M., Gemmell, N. J., Rand, T. A., and Ewers, R. M. (2007). Interactive effects of habitat modification and species invasion on native species decline. Trends Ecol. Evol. 22, 489-496. doi: 10.1016/j.tree.2007.07.001

Diepenbrock, L. M., Fothergill, K., Tindall, K. V., Losey, J. E., Smyth, R. R., and Finke, D. L. (2016). The influence of exotic lady beetle (Coleoptera: Coccinellidae) establishment on the species composition of the native lady beetle community in Missouri. Environ. Entomol. 45, 855-864. doi: $10.1093 / \mathrm{ee} / \mathrm{nvw} 065$

Dingle, H. (1984). "Behavior, genes, and life histories: complex adaptations in uncertain environments," in A New Ecology: Novel Approaches to Interactive Systems, eds P. W. Price, C. N. Slobodchikoff, and W. S. Gaud (New York, NY: John Wiley \& Sons, Inc.), 169-194.

Ehler, L. E. (1990). "Introduction strategies in biological control of insects," in Critical Issues in Biological Control, eds M. Mackauer, L. E. Ehler, and J. Roland (Andover; Hants: Intercept Ltd.), 111-134.

Elliott, N., Kieckhefer, R., and Kauffman, W. (1996). Effects of an invading coccinellid on native coccinellids in an agricultural landscape. Oecologia 105, 537-544. doi: 10.1007/BF00330017

Elton, C. S. (1958). The Ecology of Invasions by Animals and Plants. London: Methuen.

Evans, E. W. (1991). Intra versus interspecific interactions of lady beetles (Coleoptera: Coccinellidae) attacking aphids. Oecologia 87, 401-408. doi: 10.1007/BF00634598

Evans, E. W. (2000). Morphology of invasion: body size patterns associated with establishment of Coccinella septemptunctata in western North America. Eur. J. Entomol. 97, 469-474. doi: 10.14411/eje.2000.072

Evans, E. W. (2004). Habitat displacement of native North American ladybirds by an introduced species. Ecology 85, 637-647. doi: 10.1890/03-0230

Evans, E. W. (2015). Rapid but limited aggregation of ladybird beetles (Coleoptera: Coccinellidae) in response to sugar availability in the field. Acta Soc. Zool. Biochem. 79, 65-71.

Evans, E. W., and Richards, D. R. (1997). Managing the dispersal of ladybird beetles (Col.: Coccinellidae): use of artificial honeydew to manipulate spatial distributions. Entomophaga 42, 93-102. doi: 10.1007/BF027 69884

Evans, E. W., and Swallow, J. G. (1993). Numerical responses of natural enemies to artificial honeydew in Utah alfalfa. Environ. Entomol. 22, 1392-1401. doi: $10.1093 /$ ee/22.6.1392

Evans, E. W., and Youssef, N. N. (1992). Numerical responses of aphid predators to varying prey density among Utah alfalfa fields. J. Kansas Entomol. Soc. 65, $30-38$.

Evans, E. W., Soares, A., and Yasuda, H. (2011). Invasions by ladybugs, ladybirds, and other predatory beetles. Biocontrol 5, 597-611. doi: 10.1007/s10526011-9374-6
Fothergill, K., and Tindall, K. V. (2010). Lady beetle (Coleoptera: Coccinellidae: Coccinellinae) occurrences in southeastern Missouri agricultural systems: differences between 1966 and present. Coleopterists Bull. 64, 379-382. doi: 10.1649/0010-065X-64.4.379

Fox, C. W., Czesak, M. E., Mousseau, T. A., and Roff, D. A. (1999). The evolutionary genetics of an adaptive maternal effect: egg size plasticity in a seed beetle. Evolution 53, 552-560. doi: 10.1111/j.1558-5646.1999.tb03790.x

Gao, Y., and Reitz, S. R. (2017). Emerging themes in our understanding of species displacements. Аnnu. Rev. Entomol. 62, 165-183. doi: 10.1146/annurev-ento-031616-035425

Goodharzy, K., and Davis, D. W. (1958). Natural enemies of the spotted alfalfa aphid in Utah. J. Econ. Entomol. 51, 612-616. doi: 10.1093/jee/51.5.612

Gordon, R. D. (1985). The Coccinellidae (Coleoptera) of America north of Mexico. J. N. Y. Entomol. Soc. 93,1-91.

Grabock, K., Tidemann, C. R., Wood, J. T., and Lindenmayer, D. B. (2014). Are invasive species drivers of native species decline or passengers of habitat modification? A case study of the impact of the common myna (Acridotheres tristis) on Australian bird species. Austral. Ecol. 39, 106-114. doi: 10.1111/aec.12049

Grez, A. A., Zaviezo, T., Roy, H. E., Brown, P. M. J., and Bizama, G. (2016). Rapid spread of Harmonia axyridis in Chile and its effects on local coccinellid biodiversity. Divers. Distrib. 22, 982-994. doi: 10.1111/ddi.12455

Gullan, P. J., and Cranston, P. S. (2014). The Insects. An Outline of Entomology, 5th $E d n$. New York, NY: Wiley-Blackwell.

Gurevitch, J., and Padilla, D. K. (2004). Are invasive species a major cause of extinctions? Trends Ecol. Evol. 19, 470-474. doi: 10.1016/j.tree.2004.07.005

Harmon, J. P., Stephens, E., and Losey, J. (2007). The decline of native coccinellids (Coleoptera: Coccinellidae) in the United States and Canada. J. Insect Conserv. 11, 85-94. doi: 10.1007/s10841-006-9021-1

Hesler, L. S., and Kieckhefer, R. W. (2008). Status of exotic and previously common native coccinellids (Coleoptera) in South Dakota landscapes. J. Kans. Entomol. Soc. 81, 29-49. doi: 10.2317/JKES-704.11.1

Hesler, L. S., Catangui, M. A., Losey, J. E., Helbig, J. B., and Mesman, A. (2009). Recent records of Adalia bipuctata (L.), Coccinella transversoguttata richardsoni Brown, and Coccinella novemnotata Herbst (Coleoptera: Coccinellidae) from South Dakota and Nebraska. Coleopterists Bull. 63, 475-484. doi: 10.1649/1189.1

Hodek, I., van Emden, H. F., and Honek, A. (2012). Ecology and Behaviour of the Ladybird Beetles (Coccinellidae). Oxford: Blackwell Publishing Ltd.

Hoki, E., Losey, J., and Ugine, T. A. (2014). Comparing the consumptive and non-consumptive effects of a native and introduced lady beetle on pea aphids (Acyrthosiphon pisum). Biol. Control 70, 78-84. doi: 10.1016/j.biocontrol.2013.12.007

Honek, A., Martinkova, Z., Dixon, A. F. G., Roy, H. E., and Pekar, S. (2016). Longterm changes in communities of native coccinellids: population fluctuations and the effect of competititon from an invasive non-native species. Insect Conserv. Divers. 9, 202-209. doi: 10.1111/icad.12158

Kajita, Y., Obrycki, J. J., Sloggett, J. J., Evans, E. W., and Haynes, K. F. (2014). Do defensive chemicals facilitate intraguild predation and influence invasion success in ladybird beetles? J. Chem. Ecol. 40, 1212-1219. doi: 10.1007/s10886-014-0513-2

Kenis, M., Adriaens, T., Brown, P. M. J., Katsanis, A., San Martin, G., Branquart, E., et al. (2017). Assessing the ecological risk posed by a recently established invasive alien predator: Harmonia axyridis as a case study. Biocontrol 62, 341-354. doi: 10.1007/s10526-016-9764-x

Koch, R. L. (2011). Recent detections of a rare native lady beetle, Coccinella novemnotata (Coleoptera: Coccinellidae), in Minnesota. Great Lakes Entomol. 44, 196-199.

Kraus, F. (2015). Impacts from invasive reptiles and amphibians. Annu. Rev. Ecol. Evol. Syst. 46, 75-97. doi: 10.1146/annurev-ecolsys-112414-054450

Losey, J., Perlman, J., Kopko, J., Ramsey, S., Hesler, L., Evans, E., et al. (2012). Potential causes and consequences of decreased body size in field populations of Coccinella novemnotata. Biol. Control 61, 98-103. doi: 10.1016/j.biocontrol.2011.12.009

Obrycki, J. J., Elliott, N. C., and Giles, K. L. (2000). "Coccinellid introductions: potential for and evaluation of non-target effects," in Nontarget Effects of Biological Control, eds P. A. Follett and J. J. Duan (Boston, MA: Kluwer Acad. Publ.), 127-145. 
Ricciardi, A., Hoopes, M. F., Marchetti, M. P., and Lockwood, J. L. (2013). Progress toward understanding the ecological impacts of nonnative species. Ecol. Monogr. 83, 263-282. doi: 10.1890/13-0183.1

Roy, H. E., and Brown, P. M. J. (2015). Ten years of invasion: Harmonia axyridis (Pallas) (Coleoptera: Coccinellidae) in Britain. Ecol. Entomol. 40, 336-348. doi: 10.1111/een.12203

Roy, H. E., Brown, P. M. J., Adriaens, T., Berkvens, N., Borges, I., ClusellaTrullas, S., et al. (2016). The harlequin ladybird, Harmonia axyridis: global perspectives on invasion history and ecology. Biol. Invasions 18, 997-1044. doi: 10.1007/s10530-016-1077-6

Ruesink, J. L., Parker, I. M., Groom, M. J., and Kareiva, P. M. (1995). Reducing the risks of nonindigenous species introductions. BioScience 45, 465-477. doi: $10.2307 / 1312790$

SAS Institute (2011). PROC User's Manual, 6th Edn. Cary, NC: SAS Institute.

Sax, D. F., Stachowicz, J. J., Brown, J. H., Bruno, J. F., Dawson, M. N., Gaines, S. D., et al. (2007). Ecological and evolutionary insights from species invasions. Trends Ecol. Evol. 22, 465-471. doi: 10.1016/j.tree.2007.06.009

Schaefer, P. W., Dysart, R. J., and Specht, H. B. (1987). North American distribution of Coccinella septempunctata (Coleoptera: Coccinellidae) and its mass appearance in coastal Delaware. Environ. Entomol. 16, 368-373. doi: $10.1093 /$ ee/16.2.368

Simberloff, D., and Stiling, P. (1996). How risky is biological control? Ecology 77, 1965-1974. doi: 10.2307/2265693

Sugiura, S. (2016). Impacts of introduced species on the biota of an oceanic archipelago: the relative importance of competitive and trophic interactions. Ecol. Res. 31, 155-164. doi: 10.1007/s11284-016-1336-0

Tumminello, G., Ugine, T. A., and Losey, J. E. (2015). Intraguild interactions of native and introduced coccinellids: the decline of a flagship species. Environ. Entomol. 44, 64-72. doi: 10.1093/ee/nvu010

Turnipseed, R. K., Ugine, T. A., and Losey, J. E. (2014). Effect of prey limitation on competitive interactions between a native lady beetle, Coccinella novemnotata, and an invasive lady beetle, Coccinella septempunctata (Coleoptera: Coccinellidae). Environ. Entomol. 43, 969-976. doi: 10.1603/EN14043

Turnipseed, R. K., Ugine, T. A., and Losey, J. E. (2015). Egg predation by the introduced lady beetle, Coccinella septempunctata (Coleoptera: Coccinellidae), lowers mortality but raises relative risk for the native lady beetle, Coccinella novemnotata. PLoS ONE 10:e0118493. doi: 10.1371/journal.pone.0118493

Ugine, T. A., and Losey, J. E. (2014). Development times and agespecific life table parameters of the native lady beetle species Coccinella novemnotata (Coleoptera: Coccinellidae) and its invasive congener Coccinella septempunctata (Coleoptera: Coccinellidae). Environ. Entomol. 43, 1067-1075. doi: 10.1603/EN14053

Vitousek, P. M., D’Antonio, C. M., Loope, L. L., and Westbrooks, R. (1996). Biological invasions as global environmental change. Am. Sci. 84, 468-478.

Wheeler, A. G. Jr., and Hoebeke, E. R. (1995). Coccinella novemnotata in northeastern North America: historical occurrence and current status (Coleoptera: Coccinellidae). Proc. Entomol. Soc. Wash. 97, 701-716.

Wilcove, D. S., Rothstein, D., Dubov, J., Phillips, A., and Losos, E. (1998). Quantifying threats to imperiled species in the United States. Bioscience 48, 607-615. doi: 10.2307/1313420

Wilson, E. O. (1992). The Diversity of Life. Cambridge, MA: Belknap Press.

Conflict of Interest Statement: The author declares that the research was conducted in the absence of any commercial or financial relationships that could be construed as a potential conflict of interest.

Copyright (C) 2017 Evans. This is an open-access article distributed under the terms of the Creative Commons Attribution License (CC BY). The use, distribution or reproduction in other forums is permitted, provided the original author(s) or licensor are credited and that the original publication in this journal is cited, in accordance with accepted academic practice. No use, distribution or reproduction is permitted which does not comply with these terms. 